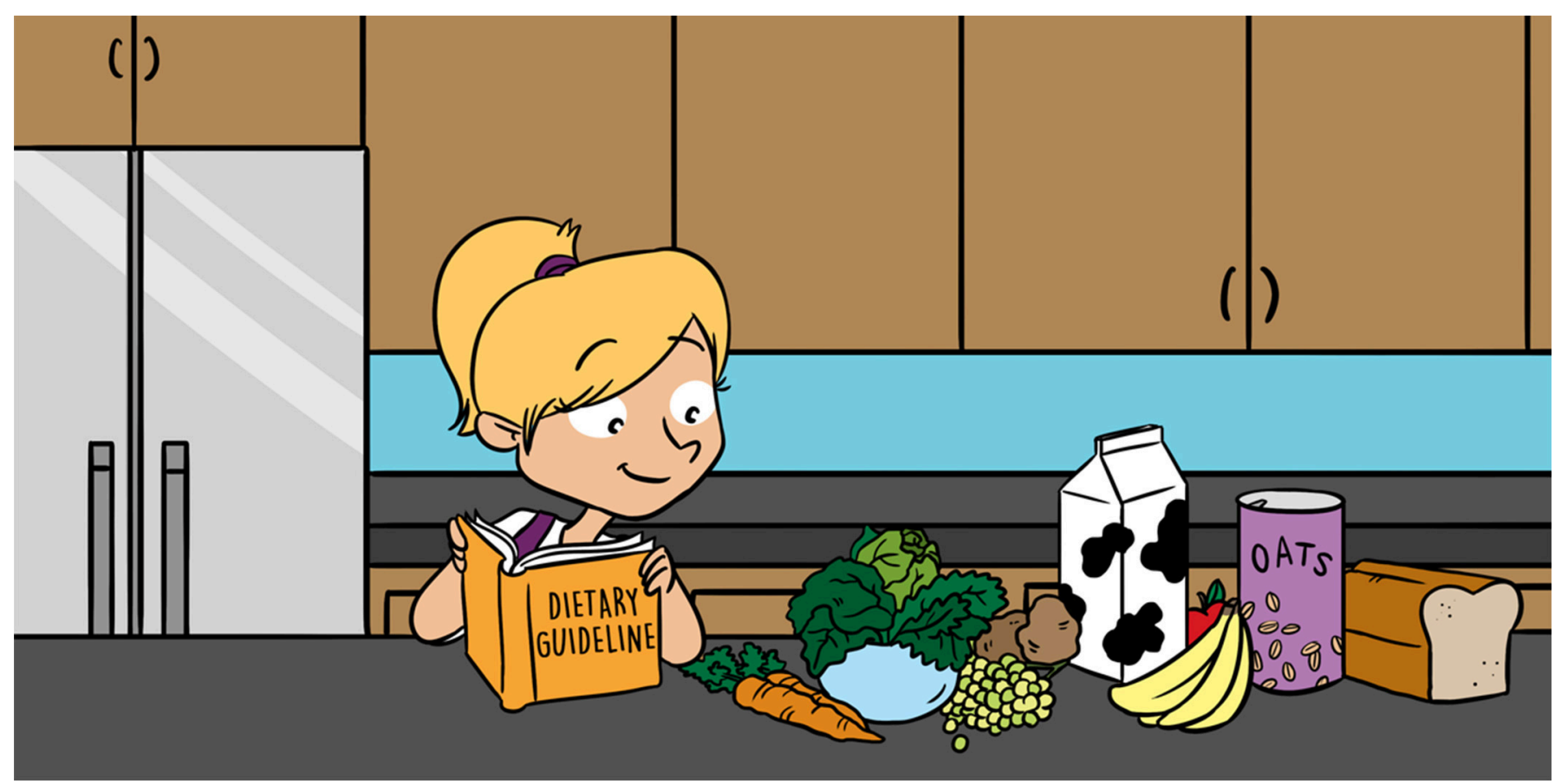

\title{
FOOD FOR THOUGHT: THE SCIENCE BEHIND DIETARY GUIDELINES
}

\section{Stephanie R. Partridge ${ }^{1,2^{*}}$, Rebecca Raeside ${ }^{1}$, Stella Ruan ${ }^{3}$ and Anna Singleton ${ }^{1}$}

${ }^{1}$ Faculty of Medicine and Health, Westmead Applied Research Centre, The University of Sydney, Sydney, NSW, Australia ${ }^{2}$ Prevention Research Collaboration, Sydney School of Public Health, The University of Sydney, Sydney, NSW, Australia ${ }^{3}$ Nutrition and Dietetics Group, School of Life and Environmental Science, The University of Sydney, Sydney, NSW, Australia

\section{YOUNG REVIEWERS:}

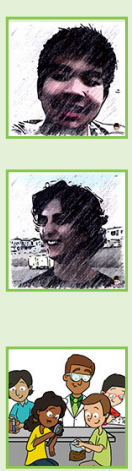

AUNG

KHANT

AGE: 15

JULIAN

AGE: 15

SCHOOL

WITHOUT

WALLS

AGE: 13
Have you ever wondered why it is important to eat vegetables every day? It starts with nutrients. Nutrients are elements in foods that our bodies use to function. The more nutrients there are in our food, the better the food is for us. Some foods, like vegetables, have a lot of nutrients so we call them "nutrient-dense." Since they say, "we are what we eat," it is important that we eat loads of nutrients to keep our bodies and minds strong and healthy. But how do we know which foods are nutrient-dense and which are not? Scientists study the link between food and health so that they can develop dietary guidelines. In this article, we talk about what dietary guidelines are and how scientists make them. We also explain why it is important to make sure dietary guidelines are reliable, according to the best available evidence. 


\section{MACRONUTRIENT}

The main nutrients that make up the foods we eat, carbohydrate, fat, and protein.

\section{MICRONUTRIENT}

Small chemical substances found in foods that our bodies require in small amounts, such as vitamin $A$, vitamin $B$, vitamin C, calcium, iron, potassium, and zinc (just to name a few!).

\section{WHAT ARE DIETARY GUIDELINES?}

Eating healthy foods throughout our lives helps us to keep our bodies and minds strong, to live long healthy lives, and to prevent diseases. But how and why do we know what foods to eat most? To guide us, scientists, governments, and other experts do a step-by-step review of the scientific evidence about food and health to develop dietary guidelines. Dietary guidelines provide us with advice on healthy eating [1]. We can think of foods as delivery trucks that are filled with nutrients to deliver to our bodies. Nutrients are elements in foods that our bodies use to function. There are two groups of nutrients in foods, macronutrients, and micronutrients. Macronutrients, including carbohydrates, protein, and fats, are the main components of foods and provide energy for us to move and function. Micronutrients, like vitamins and minerals, such as vitamin C, calcium and iron, are elements that our bodies need in small amounts for healthy growth and development. If our bodies do not get enough nutrients, we could get sick and develop diseases. The amounts of nutrients that our bodies need can be different depending on our activity level and age. For example, if you are an athlete and are very active, you may be required to eat more, because your body is working harder than the average person and using more energy. We can use dietary guidelines to guide us about what foods we should eat to get the required nutrients our bodies need to be active, healthy, grow, and prevent diseases.

\section{DIETARY GUIDELINES AROUND THE WORLD}

Dietary guidelines are specific to the country where we live. More than 100 countries around the world have created food-based dietary guidelines. All countries should develop their own dietary guidelines, because the foods that each country can grow or has access to are different. For example, warm countries like Australia have access to lots of mangos, because they grow there, but mangoes might be harder to get in Iceland, because they do not grow well in cooler climates. Also, dietary guidelines consider a country's culture, which effects what types of foods the people eat there. For example, the Sri Lankan dietary guidelines encourage rice and yams, as these foods are a part of many traditional Sri Lankan cultural dishes.

\section{HOW ARE DIETARY GUIDELINES DEVELOPED?}

To develop dietary guidelines, a team of experts, including scientists, health professionals like dietitians and nutritionists, and people from the government work together. The expert team reviews the current scientific evidence for links between foods, dietary patterns, and health outcomes. We will use the Australian Dietary Guidelines as an example. To develop these guidelines, a team of experts formed 


\section{DIET}

The kinds of foods that a person usually eats.

\section{BIAS (IN RESEARCH)}

A liking or preference for or against an outcome or result especially in a way considered to be unfair a "working committee" [2]. The working committee reviewed over 55,000 scientific studies to translate the science into dietary advice. To do this, they use a step-by-step scientific method to review primary studies (which are studies that collect new data). This scientific method is called systematic review, which answer a clear question according to a step-by-step plan. For example, "does eating a certain amount of vegetables affect a person's risk of heart disease?" The working committee would answer this question by looking at all the primary studies about this topic from around the world. Like Sherlock Holmes in a big crime case, the scientists look for evidence in the primary studies to answer their question. They then bring all the evidence together to create a summary, which is called an "evidence statement." The evidence statements are then given a grade, like at school, from A to D. Grade "A" means the scientific evidence that forms a link between dietary patterns and health is strong and can be trusted and included in the dietary guidelines. In our example, that means that scientists would recommend that people eat lots of vegetables, because it can help lower the risk of getting heart disease. Grade " $D$ " means the scientific evidence is too weak to include in the dietary guidelines. This process gives us an up-to-date summary of the scientific evidence about the relationships between food, our diet, and our health.

The next step in developing the Australian Dietary Guidelines is to turn the latest scientific evidence statements into "dietary patterns," which are plans that tell people what kinds of food are good to eat and how much and how often they should eat them. For example, a dietary plan might tell us to eat lots of healthy vegetables and fruits, but to only eat ice cream sometimes (bummer!). Dietary patterns help us stay healthy, lower our risk of diseases and help us eat enough nutrients. The working committee creates these dietary patterns using a computer program, called a "food modeling system," that figures out the amounts and types of foods that different people can eat to get the right amount of nutrients (Figure 1). The computer program makes different dietary patterns for people, based on their age, gender, activity level, or life stage. So, an old man who naps a lot will have a completely different dietary pattern from a young boy who plays lots of sports! Next, the guidelines are made available online for everyone and are updated whenever we have new scientific evidence.

\section{BIAS AND DIETARY GUIDELINES}

When we review all the scientific evidence, it may not agree with our own opinions. If we ignore the scientific evidence and favor our own opinion, this introduces something called bias (Figure 2). As we mentioned before, we can reduce this type of bias by using the step-by-step systematic review method. Systematic reviews use all primary studies, so that they can develop and grade all available evidence. To reduce bias, we also should develop dietary guidelines by a committee, not just an individual person. Members of the committee 
Figure 1

Different nutrients are hiding in our food! Nutrients are so small that we cannot see them, but we know from scientific studies the kinds and amounts of each nutrient found in different foods. We know peas have vitamin $C$, broccoli has iron, cheese is filled with protein and calcium, and bread is loaded with carbohydrates and fiber. But most of us do not have time to count all the nutrients we eat from different foods each day. It is easier to count servings of foods, like vegetables, each day. Therefore, scientists used a computer program to calculate the types and combinations of foods we should eat to get all the nutrients our bodies need each day. This makes it easy, as we only need think about foods, not the tiny micronutrients we cannot see!

\section{CONFLICT OF INTEREST}

A situation in which a person or company can gain personal benefit from actions or decisions made in their role.

\section{MALNUTRITION}

Deficiencies, excesses, or imbalances of nutrients.

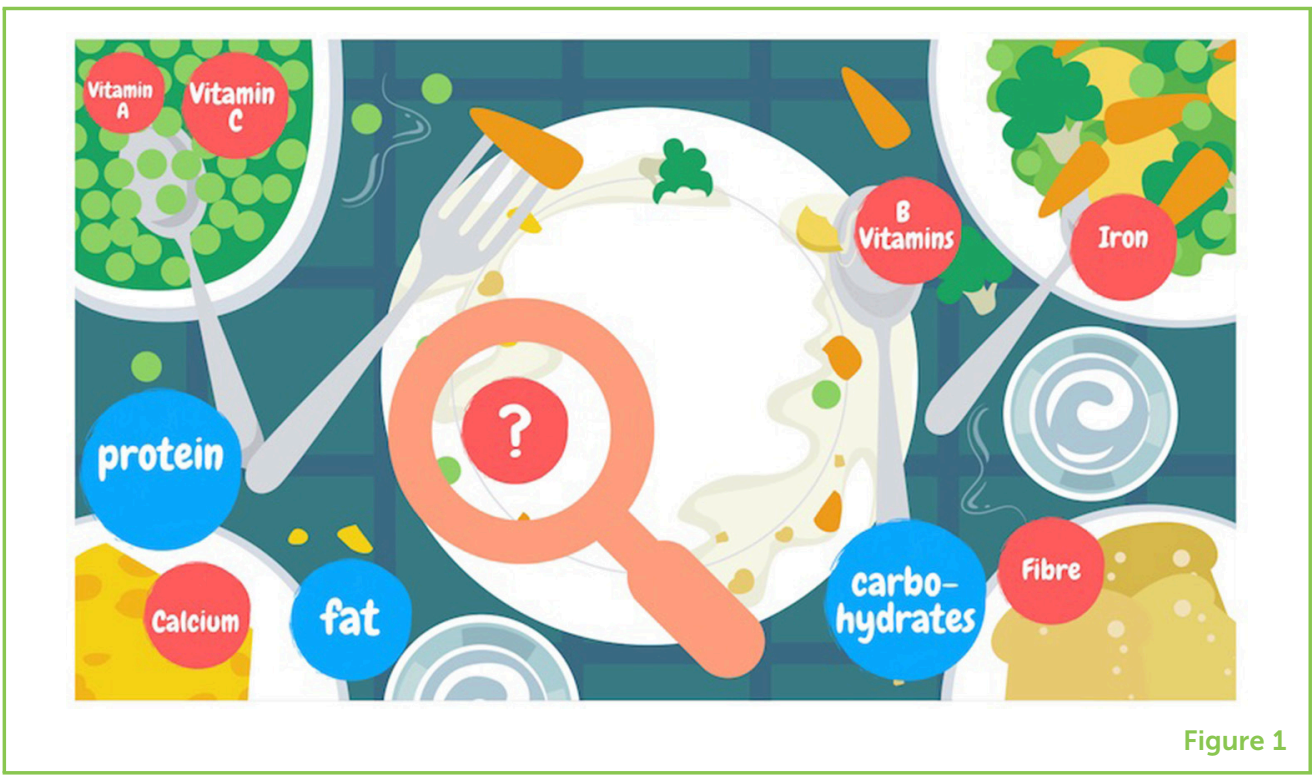

should not have any conflicts of interest. A conflict of interest is when a person's interests may influence the dietary guidelines, so it favors them. We know that some primary nutrition studies are biased if they are paid for by food companies to produce a result that favors their food or nutrient. For example, in recent years, some soda companies have paid scientists to show from their research that we do not need to worry about the negative health effects of sugary drinks, but instead focus more on exercise for our health. As scientists, we need to make sure that primary nutrition studies have low bias, so we can trust the results [3]. Many scientific journals, like this one, make authors declare if they have any conflicts of interest, so the readers know if there are possible biases.

\section{WHY ARE DIETARY GUIDELINES IMPORTANT?}

Dietary guidelines need to be correct and true, because they give us a foundation for healthy eating. These guidelines allow health researchers and scientists to develop nutrition education programs and policies to encourage healthy eating habits and lifestyles. We need dietary guidelines, because over $88 \%$ of countries around the world face malnutrition [4], which means people are eating too little or too much of certain macronutrients or micronutrients. Malnutrition can happen in two ways: undernutrition or overnutrition. Undernutrition means we are not eating enough of the good micronutrients. Overnutrition means we are eating too much of all food groups, particularly foods we should only eat occassionally that can lead to diet-related diseases, like heart disease, diabetes, and even cancer. Many countries around the world face a "double burden" of malnutrition, which means that a people can have both undernutrition (not eating enough of the right foods) and overnutrition (eating a lot of the foods we should not eat all the time). Dietary guidelines help us 


\section{Figure 2}

Bias and dietary guidelines. Scientific evidence is more important than our own opinions and feelings about food when we are trying to make decisions about dietary guidelines. For example, Sai wants the guidelines to say that Brussels sprouts are unhealthy so that he never has to eat them, and he ignores any evidence that Brussels sprouts are good for us. If we went by what Sai thinks, no one would be eating Brussels sprouts! The dietary guidelines are for everyone, including people who like Brussels sprouts, so it is important that we make sure they are fair, truthful and based on evidence.

\section{HEMOGLOBIN}

A protein in red blood cells that transports oxygen around our bodies.

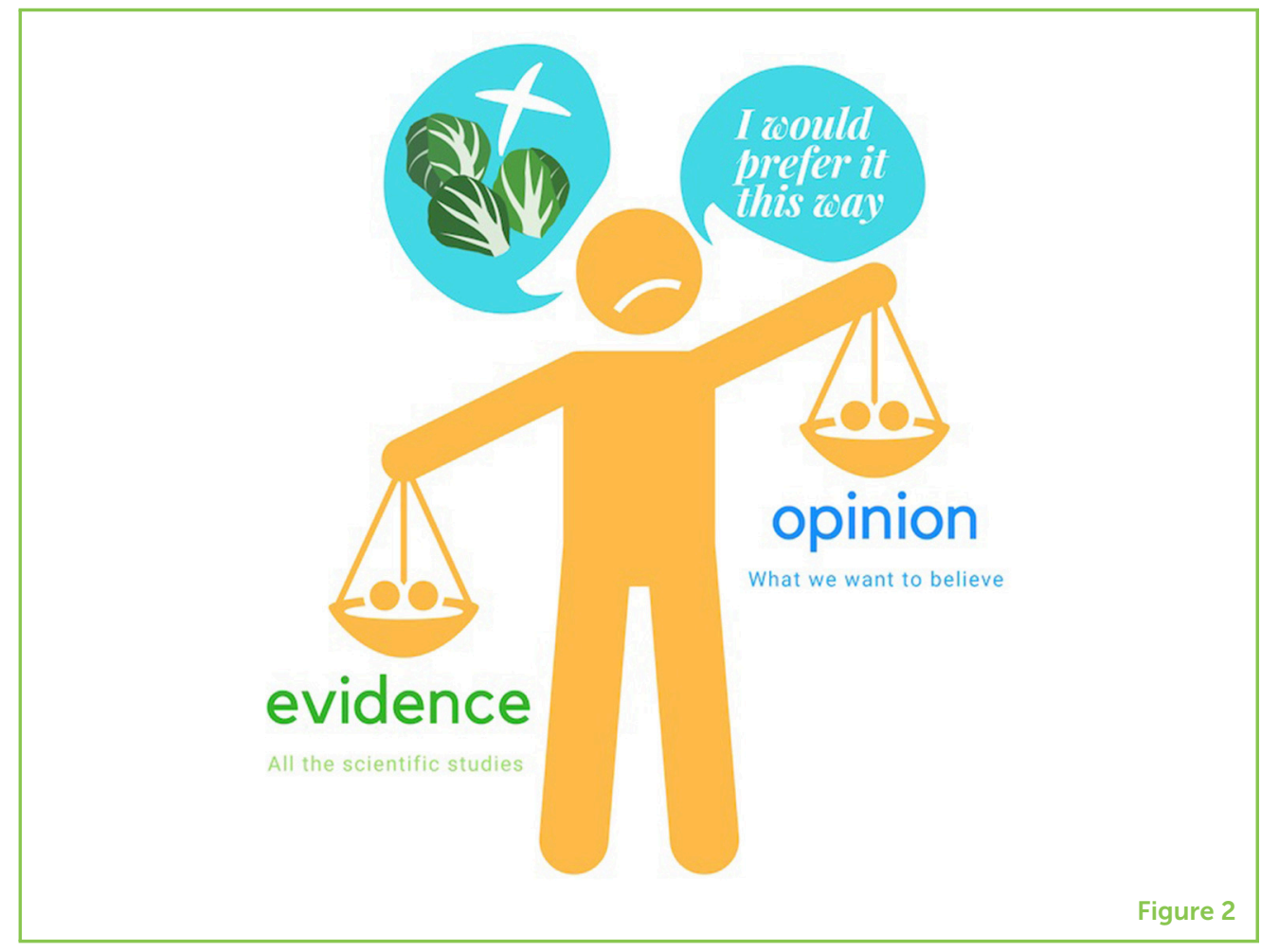

understand which foods are good should be eaten often, and which foods we should not eat as often, so that we can stay healthy and avoid getting sick.

\section{WHY DIETARY GUIDELINES ARE IMPORTANT FOR YOUNG PEOPLE LIKE YOU!}

Like we said before, our nutritional needs are different depending on our age, gender, growth stage, and activity level. You now know dietary guidelines can tell us what kinds of foods and how much we need to eat to get all the nutrients our bodies need. Since young people are still growing and are very active, it is especially important for you to eat a nutrient-dense diet, so that you can grow to be a strong and healthy adult [5]. A nutrient-dense diet contains foods that are high in nutrients, like fruits and vegetables and dairy foods, and fewer foods that are not high in nutrients, like soda and sweets. Two nutrients that are particularly important for young people are calcium and iron. Calcium is important because, during growth spurts (when you grow really fast in a short time), like puberty, young people have a lot of muscle and bone development. Calcium is a building block for our bones. During growth, our bones require double the amount of calcium. If we do not eat enough calcium-rich foods during growth, we increase our risk of developing osteoporosis (weak bones) later in life. Likewise, iron is important during growth, because of our growing blood supply. Iron is an important component of hemoglobin, which is the protein in 
Figure 3

Growth and our body's nutrient needs. Our bodies are growing until we are adults. During fast growth periods, like puberty, our bodies need more nutrients to ensure we grow up healthy and strong. Young people need more calcium and iron than adults need. For example, in the figure, Ingrid at 13 years needs 29 milligrams (mg) of calcium for each kilogram she weighs, compared with when she is an adult (18 years) and needs only $14 \mathrm{mg}$ of calcium for each kilogram she weighs. This means it is important that Ingrid eats nutrient-dense foods while growing up, so her body has all the nutrients it needs to grow and be active.

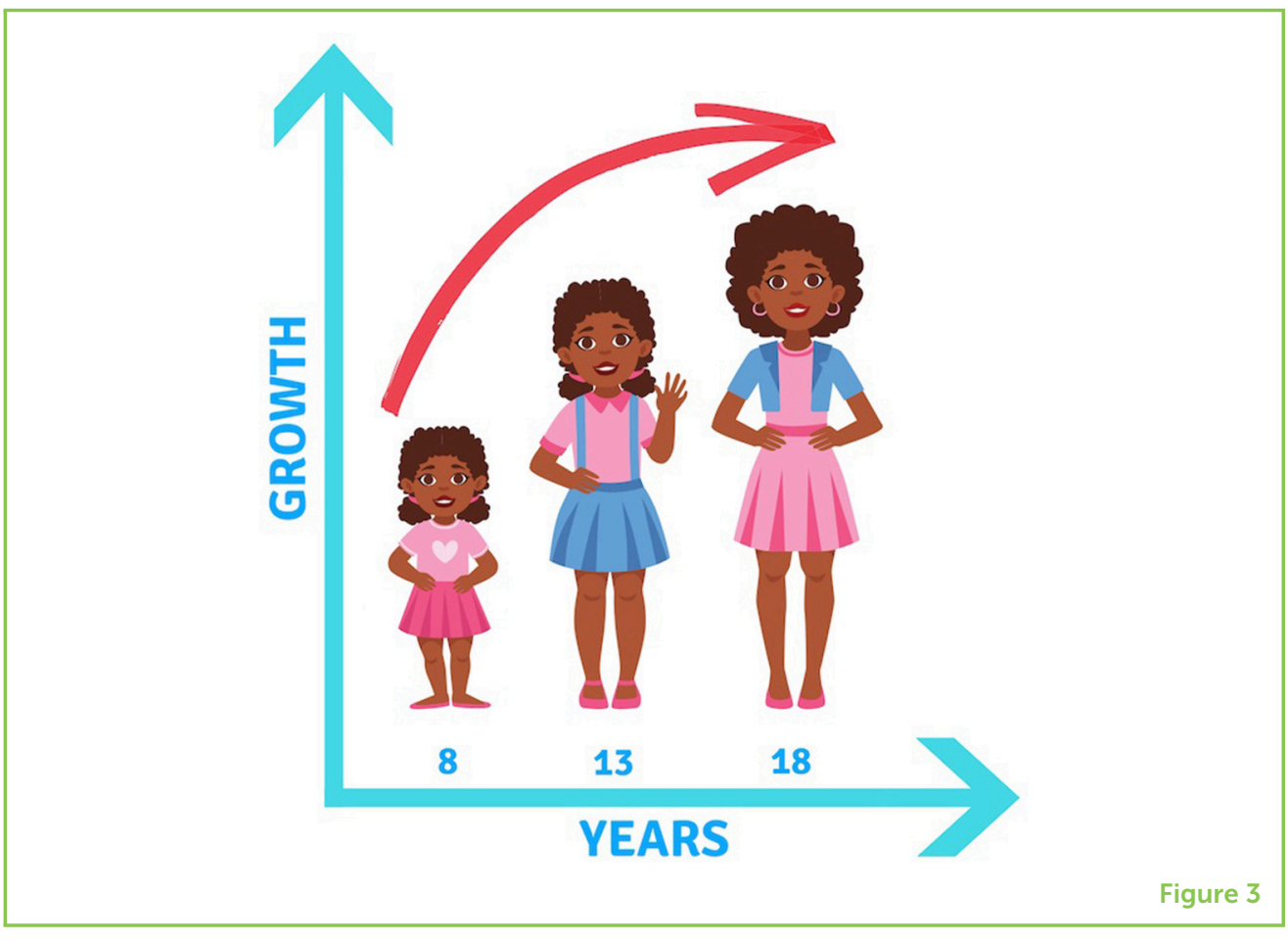

our blood responsible for transporting oxygen from our lungs to our muscles (Figure 3).

\section{SUMMARY}

In summary, we know from the scientific evidence that a healthy, nutrient-dense diet is important to keep our bodies and minds healthy and to help us live long lives and prevent diseases. Dietary guidelines give us a summary of the scientific evidence on healthy eating, which is turned into recommended servings of specific food groups each day. Therefore, it is critical that dietary guidelines are created using the best scientific methods with unbiased research evidence.

\section{REFERENCES}

1. Russell, J., Flood, V., Rochtchina, E., Gopinath, B., Allman-Farinelli, M., Bauman, A., et al. 2012. Adherence to dietary guidelines and 15-year risk of all-cause mortality. Br. J. Nutr. 109:547-55. doi: 10.1017/S0007114512001377

2. National Health and Medical Research Council. 2013. Australian Dietary Guidelines - Providing the Scientific Evidence for Healthier Australian Diets. Canberra, ACT: National Health and Medical Research Council.

3. Bero, L. 2017. Developing reliable dietary guidelines. BMJ. 359:j4845. doi: $10.1136 /$ bmj.j4845

4. World Health Organisation. 2018. Double Burden of Malnutrition. Geneva: World Health Organisation.

5. Gasser, C. E., Kerr, J. A., Mensah, F. K., and Wake, M. 2017. Stability and change in dietary scores and patterns across six waves of the Longitudinal Study of Australian Children. Br. J. Nutr. 117:1137-50. doi: 10.1017/S0007114517000897 
SUBMITTED: 30 October 2018; ACCEPTED: 28 March 2019;

PUBLISHED ONLINE: 17 April 2019.

EDITED BY: Kelly Westlake, School of Medicine, University of Maryland,

United States

CITATION: Partridge SR, Raeside R, Ruan S and Singleton A (2019) Food for Thought: The Science Behind Dietary Guidelines. Front. Young Minds 7:57. doi: 10.3389/frym.2019.00057

CONFLICT OF INTEREST STATEMENT: The authors declare that the research was conducted in the absence of any commercial or financial relationships that could be construed as a potential conflict of interest.

COPYRIGHT @ 2019 Partridge, Raeside, Ruan and Singleton. This is an open-access article distributed under the terms of the Creative Commons Attribution License (CC BY). The use, distribution or reproduction in other forums is permitted, provided the original author(s) and the copyright owner(s) are credited and that the original publication in this journal is cited, in accordance with accepted academic practice. No use, distribution or reproduction is permitted which does not comply with these terms.

\section{YOUNG REVIEWERS}

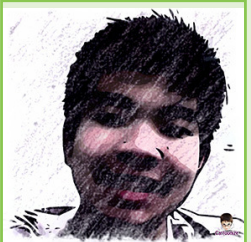

\section{AUNG KHANT, AGE: 15}

Hello, I am a 15-years-old high school student. My favorite subjects are math and science because I enjoy learning and problem solving. I plan to pursue computer engineering in the future.

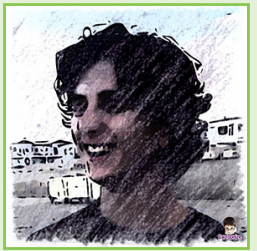

\section{JULIAN, AGE: 15}

I am a high school student interested in pursuing a career in STEM (Science, Technology, Engineering, and Mathematics). Hopefully 1 day I will be the academic sending in papers for Frontiers to review.

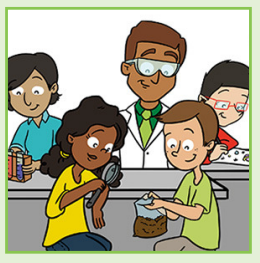

\section{SCHOOL WITHOUT WALLS, AGE: 13}

We are a group of students who are a part of the robotics club. We love to learn about new concepts emerging in math and science.

\section{AUTHORS}

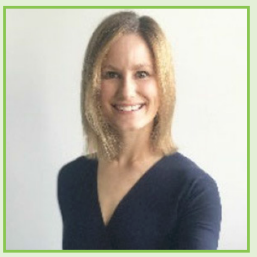

\section{STEPHANIE R. PARTRIDGE}

Stephanie is an Accredited Practicing Dietitian and public health researcher. She is passionate about helping all young people lead healthy lives and prevent chronic diseases. She is leading research into the use of digital technologies to improve 

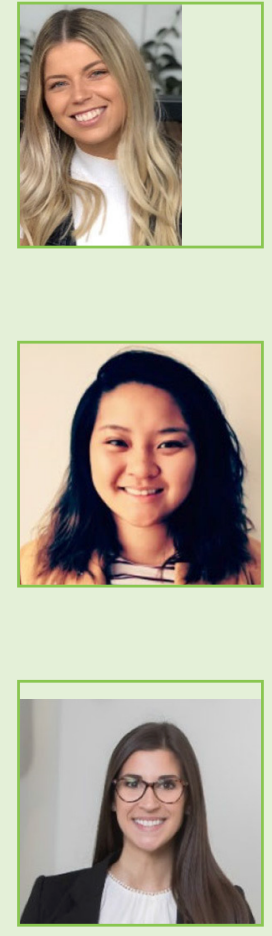

lifestyle behaviors, including eating, physical activity, and mental health behaviors in young people. By working with young people, she is hoping to improve the quality of health promotion services on offer to young people and create leadership opportunities for young people. *stephanie.partridge@ sydney.edu.au

\section{REBECCA RAESIDE}

Rebecca is a population health researcher. She works on a variety of clinical trials to help improve the health of people with chronic diseases, through changes in lifestyle behaviors. She assists in all aspects from trial design, set-up and day-to-day management. She is passionate about reducing the burden of chronic disease within the population and looking at innovative ways to achieve this.

\section{STELLA RUAN}

Stella is an Accredited Practicing Dietitian and has a Master of Nutrition and Dietetics. She has a background in exercise sport science and human nutrition. She has developed an interest in population health during her years of study. She is particularly interested in working with the youth population to provide support and intervention in helping them lead a healthy lifestyle.

\section{ANNA SINGLETON}

Anna is a psychology and public health researcher. Her undergraduate and master's degrees focused on how our brains make our arms move and how moving our arms in certain ways, like shooting a basketball 100 times, can change how our brains work. Now, Anna is leading research that aims to support women's health after breast cancer treatments, using a text message program. Co-designed with breast cancer survivors and experts, this program aims to improve women's confidence in managing their health and to help them improve in exercise, diet, and happiness. If it works, the program can be expanded to help more people. 